\title{
Microstructure and Mechanical Properties of a Novel Rapidly Solidified, High-Temperature Al-Alloy
}

\author{
N.R. Overman ${ }^{1 *}$; S.N. Mathaudhu ${ }^{1,2}$ J.P. Choi $^{1}$; T.J. Roosendaal ${ }^{1}$; S. Pitman ${ }^{1}$ \\ ${ }^{1}$ Pacific Northwest National Laboratory \\ P.O. Box 999 Richland, WA 99352 \\ ${ }^{2}$ University of California, Riverside \\ 3401 Watkins Dr. \\ Riverside, CA 92521
}

Phone: (509) 375-1913

Fax: (509) 375-3033

Nicole.Overman@pnnl.gov

\begin{abstract}
Rapid solidification (RS) processing, as a production method, offers a variety of unique properties based on far-from-equilibrium microstructures obtained through rapid cooling rates. In this study, we seek to investigate the microstructures and properties of a novel Al-alloy specifically designed for high temperature mechanical stability. Synthesis of, $\mathrm{AlFe}_{11.4} \mathrm{Si}_{1.8} \mathrm{~V}_{1.6} \mathrm{Mn}_{0.9}$ (wt. \%), was performed by two approaches: rotating cup atomization ("shot") and melt spinning ("flake"). These methods were chosen because of their ability to produce alloys with tailored microstructures due to their inherent differences in cooling rate. The as-solidified precursor materials were microstructurally characterized with electron microscopy. The results show that the higher cooling rate flake material exhibited the formation of nanocrystalline regions as well additional phase morphologies not seen in the shot material. Secondary dendritic branching in the flake material was on the order of $0.1-0.25 \mu \mathrm{m}$ whereas branching in the shot material was $0.5-1.0 \mu \mathrm{m}$.

Consolidated and extruded material from both precursor materials was mechanically evaluated at both ambient and high $\left(300^{\circ} \mathrm{C}\right)$ temperature. The consolidated RS flake material is shown to exhibit higher strengths than the shot material. The ultimate tensile strength of the melt spun flake was reported as $544.2 \mathrm{MPa}$ at room temperature and $298.0 \mathrm{MPa}$ at $300^{\circ} \mathrm{C}$. These results forecast the ability to design alloys and processing approaches with unique non-equilibrium microstructures with robust mechanical properties at elevated temperatures.
\end{abstract}

Keywords: Rapid Solidification, Aluminum Alloy, Microstructure, Cooling Rate, Flake 


\subsection{Introduction}

High temperature aluminum alloys offer a number of potential benefits that can be translated into both cost and weight savings over traditional materials such as titanium and nickel based alloys. The automotive industry in particular has invested considerably in alloy development by funding laboratory and production scale research to develop aluminum alloys that can exhibit enhanced high temperature $\left(>300^{\circ} \mathrm{C}\right)$ strength at low cost.[1-3] The need for lightweight high temperature materials is two-fold. Firstly, high performance engine components constantly undergo loading and unloading cycles that necessitate high temperature tensile and fatigue strength. Secondly, producing aluminum alloys with higher strength to weight ratios translates into direct mass reduction of engine components.[4, 5] This leads to higher engine efficiency, decreased fuel consumption and reduced environmental impact.[3, 6-8]

Traditionally, common approaches to aluminum alloying have focused on increasing strength using three primary routes; solid solution strengthening, precipitation strengthening and cold/hot working. Of the three methods discussed, precipitation strengthened 2xxx, 6xxx and 7xxx alloys make up the majority of high strength aluminum materials used in automotive/aircraft applications.[2, 5, 8] Despite their high strength to weight ratios, the application of these materials is limited to operational temperatures below $100^{\circ} \mathrm{C}-200^{\circ} \mathrm{C}$.[9] In the case of conventional precipitation strengthening, exceeding these temperatures results in an overaged material where coarsening of precipitate dispersions leads to an overall reduction in strength, and similar losses are observed in worked material due to microstructural recovery and possible recrystallization. In an effort to increase alloy strength at elevated temperature $\left(\sim 300^{\circ} \mathrm{C}\right.$ in service $\left.[2,7]\right)$, solid solution strengthening using solutes with limited diffusion at elevated temperatures presents a tractable choice in the development of new alloys.

The strength increases that can be obtained by solid solution strengthening during equilibrium solidification can be further improved using a far from equilibrium processing method such as rapid solidification (RS).[8, 10] Fast cooling rates effectively supersaturate the solid solution, through extension of solid solubility limits.[2, 6, 8, 10-12] Diffusion and migration are severely limited at cooling rates greater than $10^{3} \mathrm{~K} / \mathrm{s}$ allowing the formation of non-equilibrium phases that are disordered or ultra-refined and that display enhanced compositional flexibility.[3, 11] Incorporation of elements such as $\mathrm{Fe}, \mathrm{Si}$ and Mn that have low diffusivity in aluminum enhances the thermal stability at higher temperatures $[2,7,13]$. Microstructures that develop in rapidly solidified materials tend to exhibit non-equilibrium microstructures, including amorphous, nanocrystalline or quasicrystalline phases.[2, 3, 8, 14-17] As a result, grain size strengthening may further assist in increasing the yield point in these materials. RS alloys have also demonstrated improvements in mechanical properties such as ductility as well as fatigue and crack propagation resistance.[7]

In this study, the microstructures and mechanical properties of a novel Al-alloy designed for high temperature applications are investigated. Specifically, far-from-equilibrium microstructures are synthesized via two rapid solidification approaches, each with inherently different cooling rates. These alloys are consolidated and mechanically tested at ambient temperatures and at $300^{\circ} \mathrm{C}$. The results show that the faster cooling rate promoted by melt spinning offers finer microstructures than those produced via rotating cup atomization. The benefits of the finer microstructure are demonstrated by enhanced low and high temperature mechanical properties in the consolidated, bulk state. Furthermore, the microstructures demonstrate thermal stability against coarsening in the as-consolidated state, indicated the ability to design future materials with enhanced mechanical properties in high temperature applications.

\subsection{Material and methods}

All testing was performed on a newly-developed alloy chemistry (AFM-11), the composition of which is shown in Table 1. 
Table 1. AMF-11 alloy composition (in wt.\%).

\begin{tabular}{|c|c|c|c|c|c|}
\hline Alloy & $\mathrm{Fe}$ & $\mathrm{Si}$ & $\mathrm{V}$ & $\mathrm{Mn}$ & $\mathrm{Al}$ \\
\hline AFM-11 & 11.4 & 1.8 & 1.6 & 0.9 & $\mathrm{Bal}$. \\
\hline
\end{tabular}

Rapid solidification (RS) of the Al-Fe high temperature alloy was conducted by two different methods: melt spinning of molten aluminum to produce flake material, and rotating cup atomization to form shot material. The melt spinning method utilizes a rapidly spinning, internally cooled copper wheel. As molten metal impinges on the surface of this cooled wheel, the stream is rapidly thinned during cooling, resulting in the formation of a metallic ribbon or flake material.[18] The rotating cup processing method is similar, however, instead of a cooled copper wheel, the molten metal is directed onto a rapidly spinning cup. As metal reaches the cup, centrifugal force disperses it into fine droplets (or shot) that cool convectively; high velocity gases are commonly employed to aid the cooling process.[19] Production of these materials was performed in an argon atmosphere. The cooling rate differences between these two methods are known to differ by several orders of magnitude and have been estimated using the secondary dendrite arm spacing.

Following fabrication of the RS flake or shot, these feedstock materials were subsequently canned, cold compacted and consolidated by vacuum hot pressing at $450^{\circ} \mathrm{C}$ to $\sim 90 \%$ theoretical density to form billets. The consolidated billets of both materials were then extruded at elevated temperature $\left(\sim 480^{\circ} \mathrm{C}\right)$. Some additional melt spun flake material underwent an additional forging step $\left(\sim 480^{\circ} \mathrm{C}\right)$. Identical pressing and extrusion parameters were used for both materials. The billet diameter was $50 \mathrm{~mm}$ and extrusions were produced using a 19:1 ratio, with a final diameter of $11.4 \mathrm{~mm}$.

After extrusion, a minimum of three tensile specimens were produced. Tensile specimens were machined according to ASTM E8/E8M-09 and tested with the use of an Instron MTS 8800 tension tester. Sample sets were evaluated at both room temperature and elevated temperatures $\left(300^{\circ} \mathrm{C}\right)$ with a crosshead speed of $0.005 \mathrm{in} / \mathrm{min}$. Crosshead displacement as well as extension of the specimen gage was measured.

Polished cross sections of the material were then fabricated and evaluated with a JEOL 7600 FESEM. Microstructural analysis and energy dispersive x-ray spectroscopy (EDS) examination of the specimens were performed both parallel and perpendicular to the extrusion direction to evaluate microstructural features and morphologies of the produced material.

\subsection{Results \& Discussion}

\subsection{Rapidly Solidified Shot Precursor Material}

In the 'as-solidified' state significant structural differences were observed between the rapidly solidified shot and flake material. This variation was expected due to the significant cooling rate differences between the two production methods. Both the melt spinning and rotating cup processing generated materials with a wide array of microstructures, differing primarily in length scale. As an example, secondary dendritic branching in the flake material was on the order of $0.10-0.25 \mu \mathrm{m}$ whereas branching in the shot material was $0.5-1.0 \mu \mathrm{m}$. As seen in Figure 1, the shape of shot is similar to a water droplet with elongation in the direction of the centrifugal force. The larger microstructural features of the shot material can be easily understood due to the comparatively slower cooling rates associated with this processing method over the melt spinning technique. 




Figure 1. Microstructural features seen in the room temperature rotating cup processed shot material a) dendrites b) angular precipitates of two different compositions (possibly primary phases) and c) rosettes.

EDS data was collected from each of the different shot material morphologies and is presented in Figure 2. The matrix phase consists primarily of aluminum. Dispersed between the rosette structures in Figure 1c are areas of weak backscatter contrast that correspond to silicon enrichment (figure 2). The composition of these regions is approximately $70 \mathrm{wt} . \% \mathrm{Al}$ and $30 \mathrm{wt} . \% \mathrm{Si}$, compositions were identified by using local area analysis of the EDS spectra.
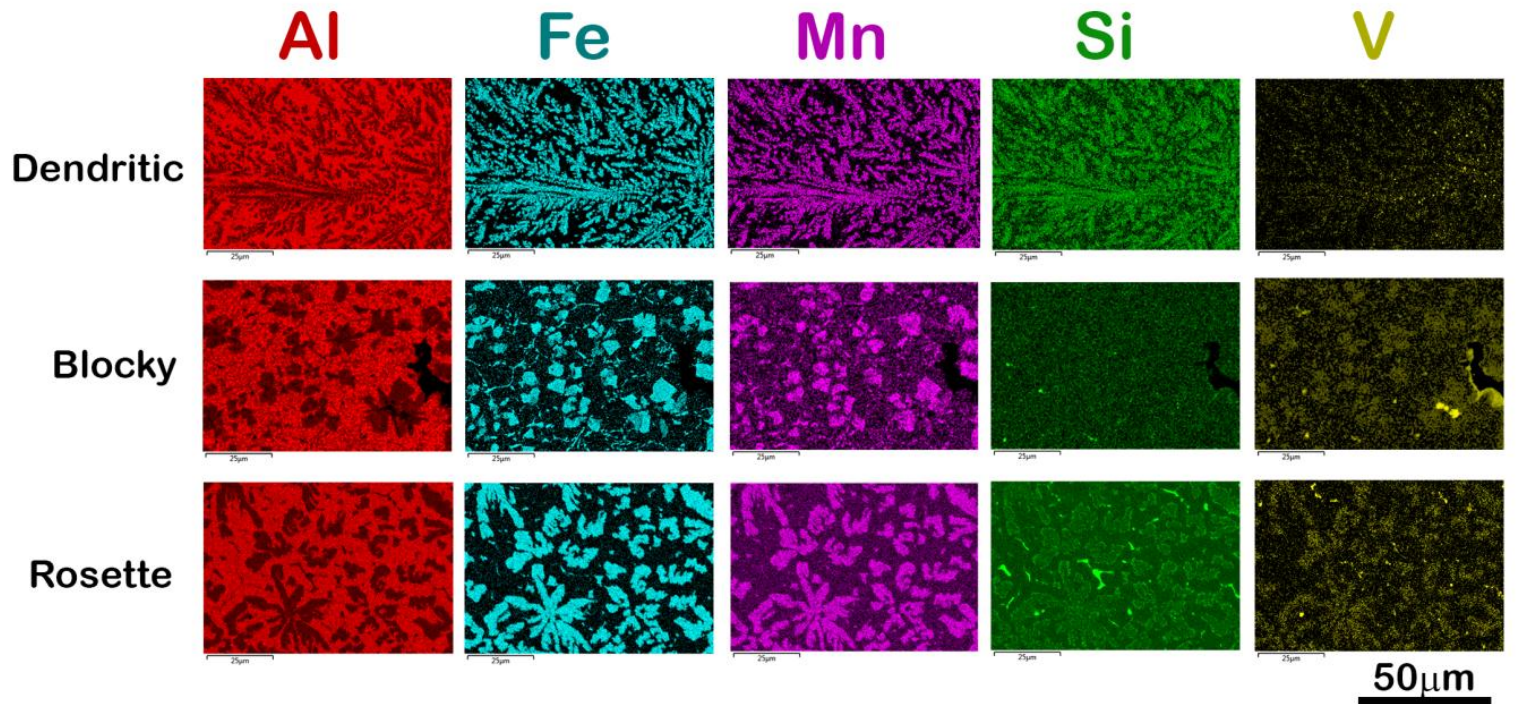

Figure 2. Elemental EDS maps of the different microstructural features seen in the shot material. The specimen matrix was identified as $100 \mathrm{wt}$.\% Aluminum (identified from the EDS spectra) for all morphologies shown, the unique microstructural features were shown vary in secondary alloying elements. 
EDS sum spectra of the entire mapped region were overlaid and are shown in Figure 3. The dendritic phase was shown to have the highest iron content, followed by the rosette structure. The block-like, angular phase had the lowest iron concentration as well as the lowest Si concentration.

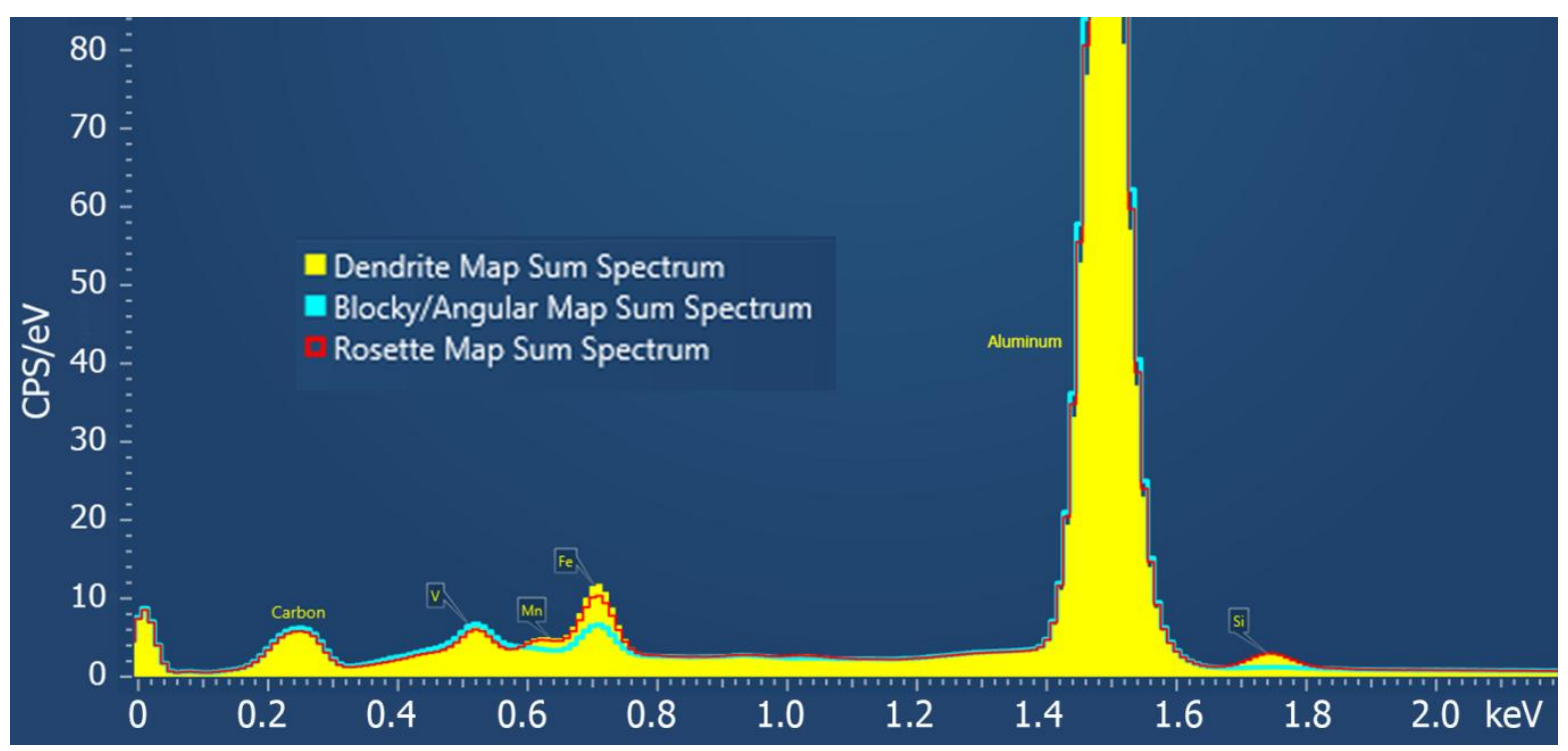

Figure 3. Overlaid EDS sum spectra of the entire mapped region shown in Figure 2. The overlaid plots indicate iron and silicon compositional variations are present in the different morphologies.

The decrease in both iron and silicon solubility are likely a result of cooling rate variation in the produced shot material. The increased solubility of iron and silicon in the dendritic structure indicates this morphology formed as a result of a faster cooling rate, followed by the rosette structure and finally the blocky/angular morphology. A significant body of literature has been devoted to estimating cooling rates in RS materials through measurement of the secondary dendrite arm spacing. Figure 4 below shows secondary dendrite arm spacing that was measured and used to calculate an average spacing of $0.72 \mu \mathrm{m} \pm$ $0.2 \mu \mathrm{m}$.

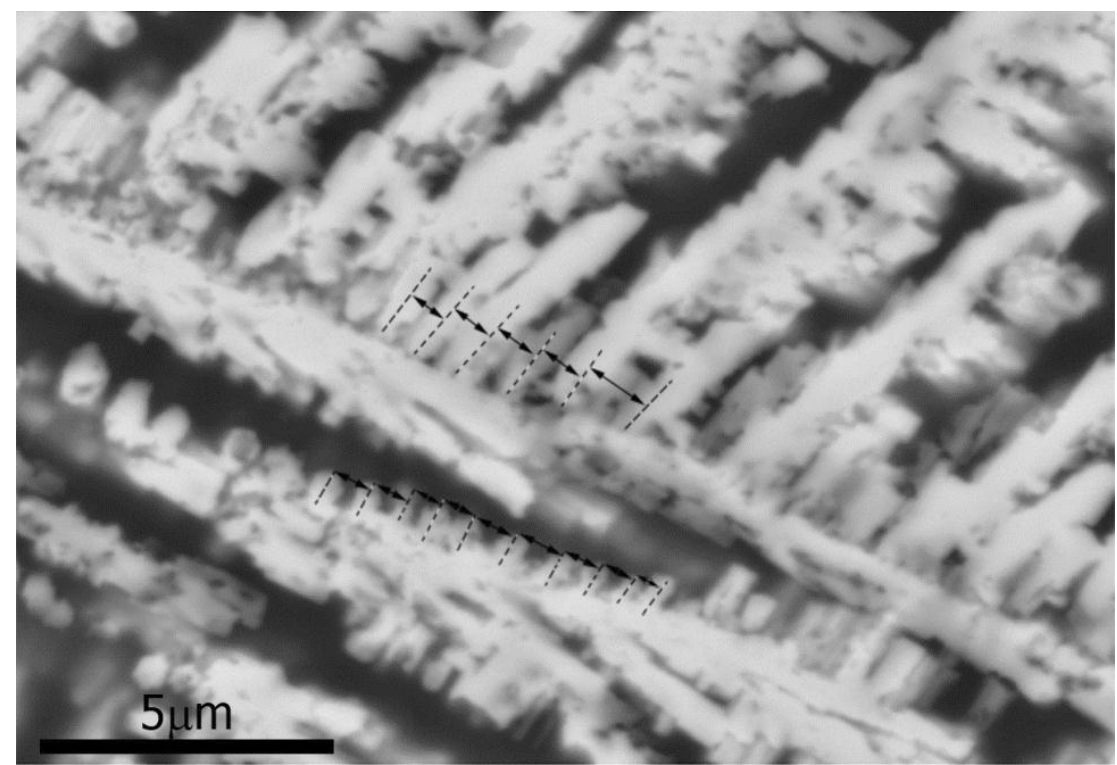

Figure 4. Electron backscatter image showing dendritic phased formed in the RS shot material. Secondary dendrite arm spacing is indicated. 
While exact calculation of the cooling rate is dependent on diffusion coefficients and therefore alloy composition, an approximation of the cooling rate for aluminuim alloys based on the work of Dobatkin, et.al.[20] indicates the cooling rate for the shot material is likely in the range $10^{4}-10^{6} \mathrm{~K} / \mathrm{s}$.

\subsection{Rapidly Solidified Flake Precursor Material}

The melt spinning process utilizes a spinning copper wheel to produce the RS flake. The wheel is scribed with a special knurled pattern of lines, running both in the direction of rotation and perpendicular to it. This surface pattern produces discontinuous flakes that are approximately $1 \mathrm{~mm} \times 1 \mathrm{~mm}$ square, with a thickness of $35 \mu \mathrm{m}$ to $55 \mu \mathrm{m}$, depending on the operating parameters and materials. A micrograph of the cross-section of an Al-Fe RS flake is shown in Figure 5. Nanocrystalline regions are present near the wheel side of the flake. The thickness of these nanocrystalline regions is variable, and can be attributed to large thermal gradients as well as the surface variation (knurled pattern) on the spinning copper wheel.

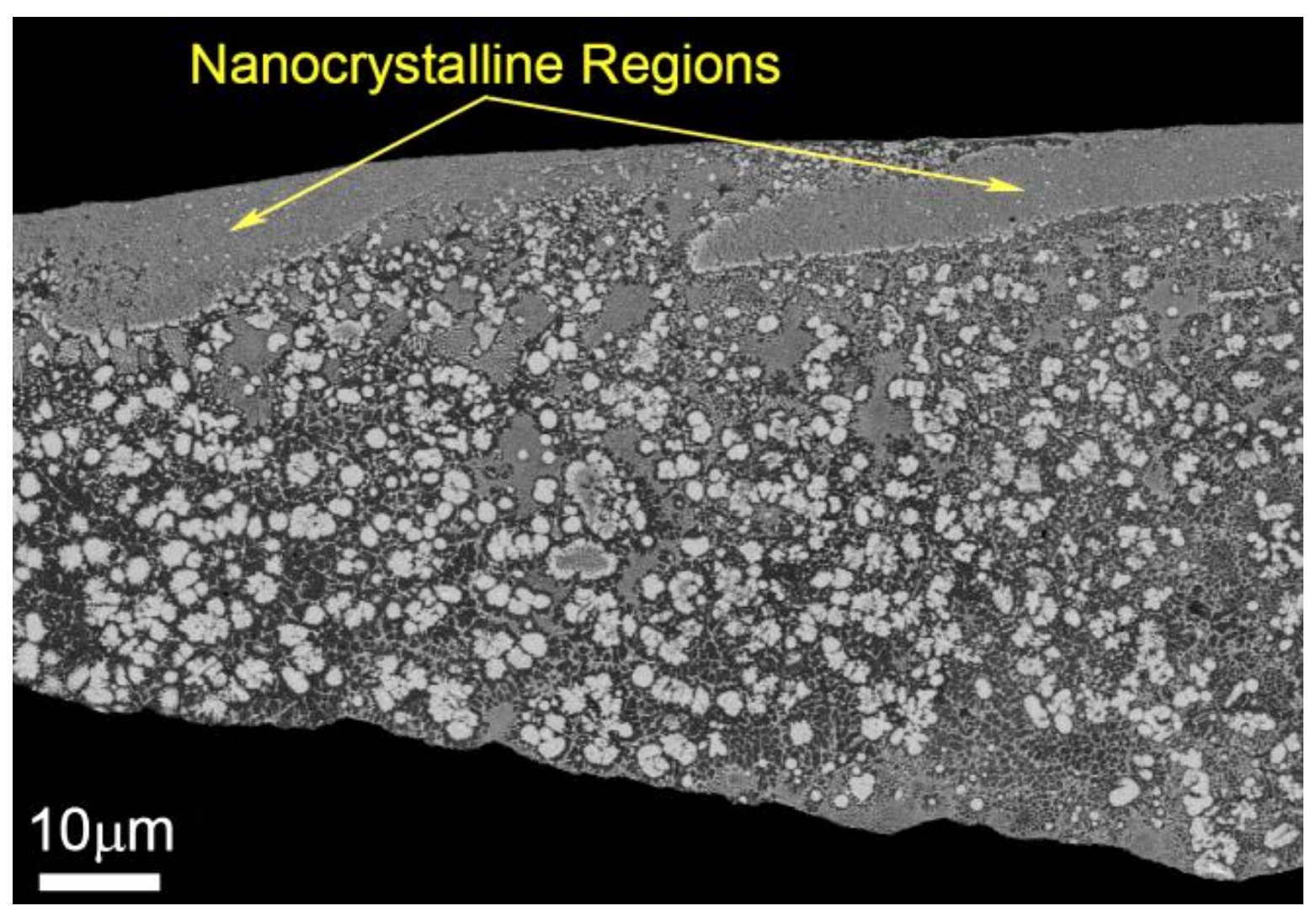

Figure 5. Backscatter electron image of the cross-section of an AFM-11 flake showing the formation of nanocrystalline regions near the wheel side.

Aside from the nanocrystalline area, an additional bright circular phase was also visible (Figure 5). EDS results indicated this phase was iron rich. The visible increase in diameter of this phase away from the wheel side of the flake is indicative of diffusion controlled growth and a cooling rate gradient through the thickness of the flake. Several other unique dispersed phases were identified in the AFM-11 material when viewed at elevated magnification including ring structures, dendritic cellular networks, and eutectic/lamellar structures that are shown in Figure 6. 



Figure 6. Microstructural variance in the room temperature flake material a) rings b) nanocrystalline regions c) dendritic-cellular network surrounding Fe-rich core d) lamella/eutectic phase

The distinct phase morphologies observed in the room temperature flake material were compared with variations seen in the shot material. Two key differences exist between the flake and shot microstructures: 1) The nanocrystalline/amorphous layer is not present in the shot material, and 2) the length scale of phases in the shot material is much larger than that of the flake.

The secondary dendrite arm spacing of the flake material was measured from several areas within Figure 7 and was found to be $0.21 \pm 0.06 \mu \mathrm{m}$. This secondary dendrite arm spacing is indicative of a cooling rate between $10^{7}-10^{9} \mathrm{~K} / \mathrm{s}$ for the flake material,[20] significantly faster than the dendrite morphology created using rotating cup atomization. 


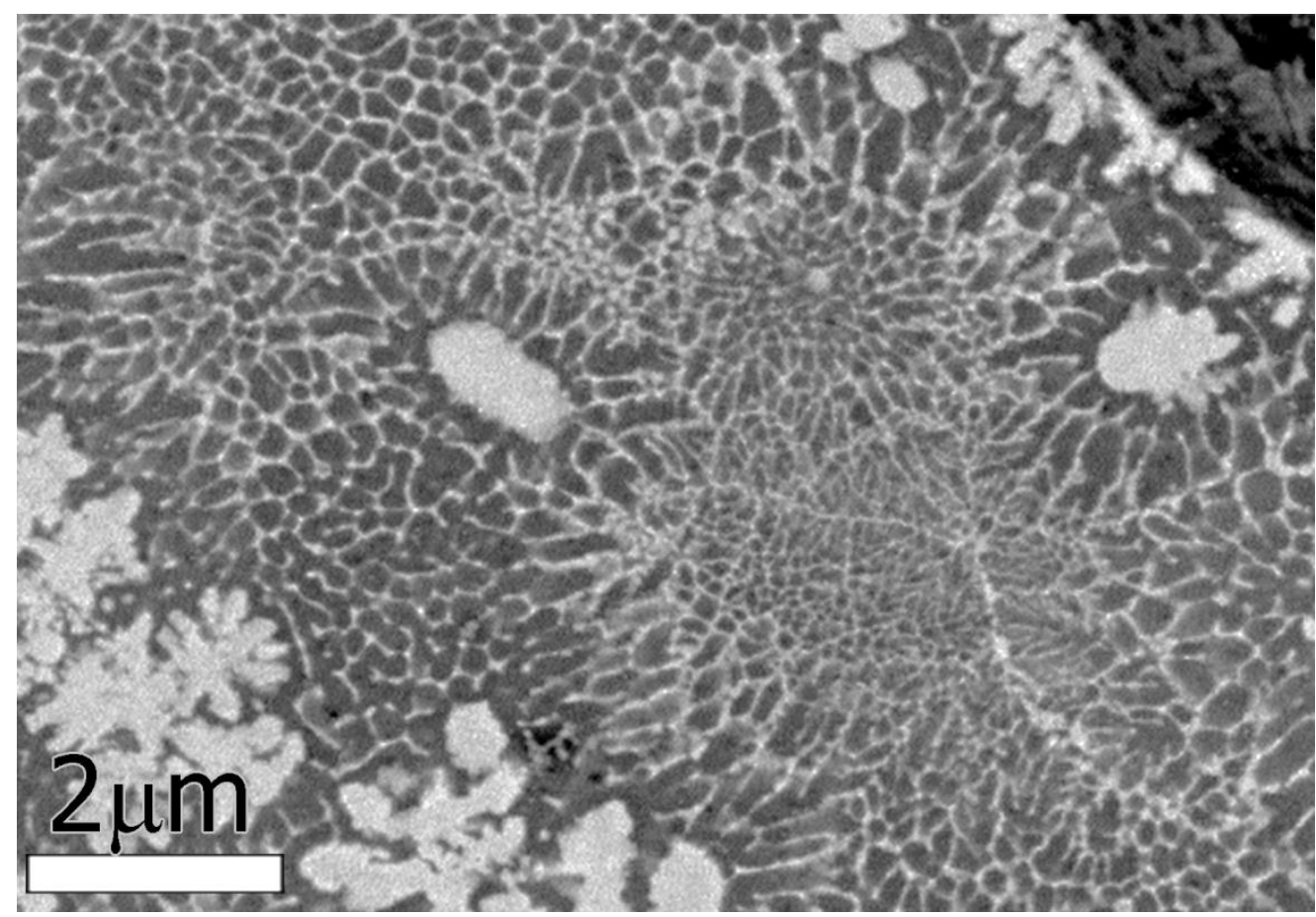

Figure 7. Low $\mathrm{kV}$ electron backscatter image showing dendritic phase formed in the RS flake material. Secondary dendrite arm spacing was measured and found to be $0.21 \pm 0.06 \mu \mathrm{m}$.

The increased cooling rate seen in the flake material, processed by melt spinning, allows for improved strengthening when compared to the shot material. Enhanced structural refinement and solid solubility of the flake as evidenced by the presence of phase morphologies not seen in the shot material (nanocrystalline, eutectic) indicates the flake material will have elevated mechanical properties.

\subsection{Consolidation of Precursors}

Following fabrication of precursors, the shot and flake materials were consolidated by hot pressing at $\sim 450^{\circ} \mathrm{C}$ and a successive extrusion at $\sim 480^{\circ} \mathrm{C}$. Processing RS material at elevated temperature is necessary for full consolidation. Despite the fact that processing temperatures have potential to alter precursor microstructures, when precursors are processed identically, the technique can be used to compare material strength and has the added benefit of removing thermal instabilities in the operating temperature regime $\left(300^{\circ} \mathrm{C}\right)$.

Because of the higher cooling rate, and therefore greater potential for formation of metastable phases and high temperature thermal instability, the flake material microstructure was evaluated in the pressed and extruded condition. As seen in Figure 8, the overall structure of the material has been significantly altered from the as-produced state, which is expected considering the level of deformation the structures have undergone during extrusion. Many of the individual phase morphologies identified in the precursor material (Figure 6) are still apparent in the consolidated flake. The ring and nanocrystalline morphologies are clearly visible while the lamellar and dendritic phases are more difficult to distinguish. These difficult-to-distinguish phases were likely sheared and further dispersed during the extrusion process, which could significantly alter their congruency, making them more difficult to identify. What appear to be remnants of these phases are shown in Figure 8. Consolidation of Al-rich regions resulted in the formation of banding in the direction of extrusion. 

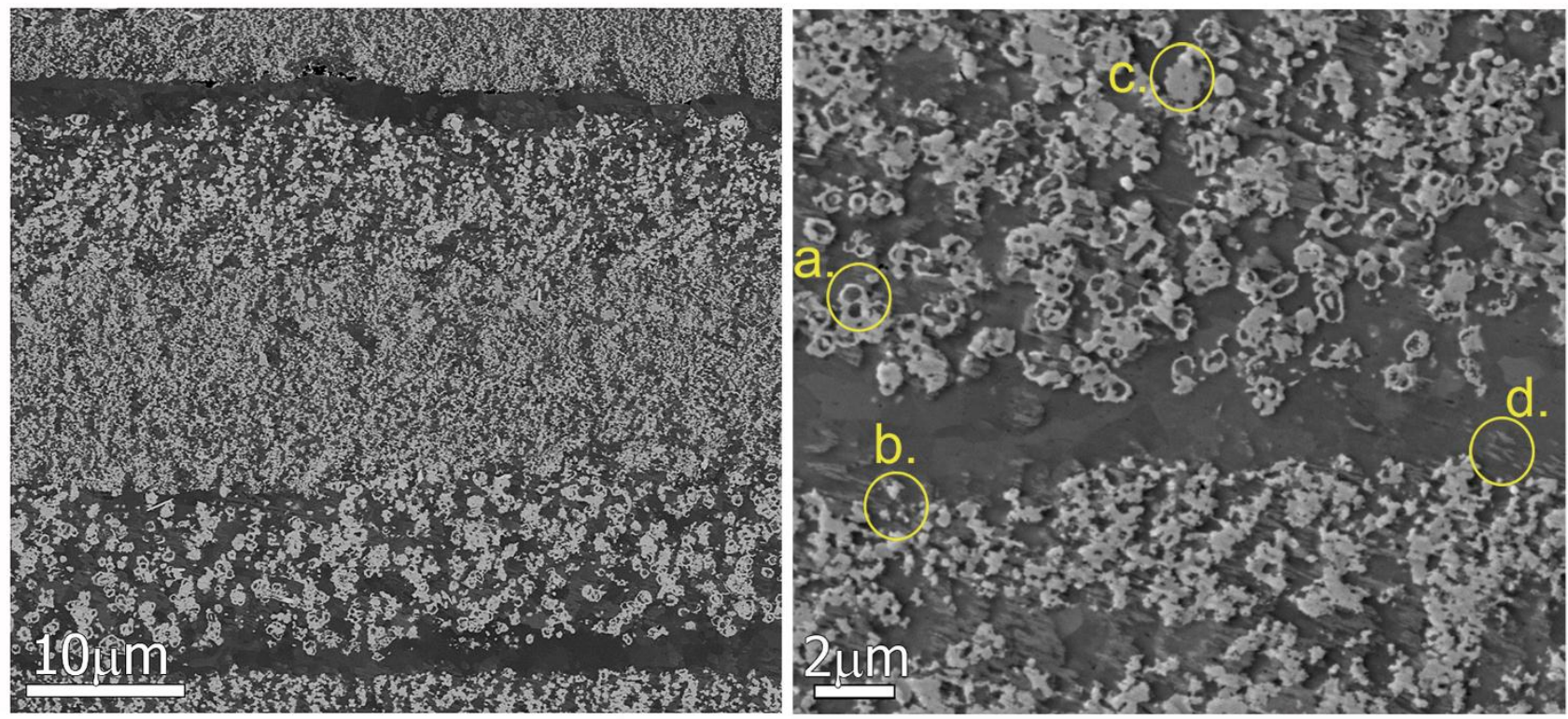
Figure 8. Left - low magnification image of structural variance in consolidated and extruded flake material, extrusion direction in horizontally aligned in the image. Right - higher magnification image illustrating phase morphologies identified in the precursor material a) rings b) nanocrystalline c) Fe-rich core and d) residual lamella/eutectic phase.

Following identical consolidation of both precursor materials, an additional high temperature step (Forging $\sim 480^{\circ} \mathrm{C}$ ) was performed on the already processed flake material. The flake material was selected to undergo this additional high temperature processing step to evaluate the potential for reduction in strength due to thermal decomposition.

\subsection{Mechanical Evaluation of Consolidated and Extruded Flake and Shot Material at Room and Elevated Temperature}

Tensile test results of the consolidated and extruded rapidly solidified material are shown in Table 2 . The failure extension is a measure of the crosshead displacement at failure. All values shown are the average of three tests performed for each condition. As expected, the more refined microstructure of the flake material resulted in dramatic increases in both the yield and ultimate tensile strength when compared to the shot material. The yield strength of the extruded flake material was in excess of $275 \mathrm{MPa}$ at $300^{\circ} \mathrm{C}$. Room temperature tests of the extruded flake material exhibited a 544.2 MPa yield strength. An additional processing condition (a forging step following the initial consolidation and extrusion) was also tested to evaluate thermal stability at temperatures significantly above $300^{\circ} \mathrm{C}$. All of the RS processed alloys exhibited tensile strength values that are significantly improved when compared to other high temperature aluminum alloys, for example the 2xxx (Al-Cu) alloys in the peak aged and extruded condition which exhibit ultimate tensile strengths $160-170 \mathrm{MPa}$ when tested at $260^{\circ} \mathrm{C}$ for 0.5 hours. [21] More complicated and expensive alloy systems such as AlFeCeCuXXX type alloys produced by melt spinning have been shown to achieve yield strengths in the range of $230-287 \mathrm{MPa}$ at $300^{\circ} \mathrm{C}$.[22] 
Table 2. Tensile Results Summary of AFM-11 Flake and Shot Material.

\begin{tabular}{|c|c|c|c|c|c|}
\hline $\begin{array}{c}\text { Alloy } \\
\text { Designation }\end{array}$ & Condition & $\begin{array}{c}\text { Test } \\
\text { Temperature } \\
\left({ }^{\circ} \mathrm{C}\right)\end{array}$ & $\begin{array}{c}\text { Yield } \\
\text { Strength } \\
(\mathrm{MPa})\end{array}$ & $\begin{array}{c}\text { Ultimate Tensile } \\
\text { Strength } \\
(\mathrm{MPa})\end{array}$ & $\begin{array}{c}\text { Failure } \\
\text { Extension } \\
(\%)\end{array}$ \\
\hline AFM-11shot & Extruded & Room & 287.0 & 411.2 & 1.8 \\
\hline AFM-11 shot & Extruded & $300^{\circ} \mathrm{C}$ & 185.6 & 185.6 & 5.8 \\
\hline AFM-11 flake & Extruded & Room & 544.2 & 544.2 & 3.6 \\
\hline AFM-11 flake & Extruded & $300^{\circ} \mathrm{C}$ & 278.4 & 298.0 & 6.1 \\
\hline AFM-11 flake & Extruded + Forged & Room & 351.3 & 360.7 & 2.7 \\
\hline AFM-11 flake & Extruded + Forged & $300^{\circ} \mathrm{C}$ & 200.0 & 202.7 & 2.1 \\
\hline
\end{tabular}

Engineering stress vs. strain plots were generated to illustrate the effects of temperature and forging on the higher strength flake material and are shown in Figure 9. The data plotted shows a representative stress vs. strain curve for each condition. Elevated temperature testing as well as the additional forging step during processing resulted in lower yield strength. The added forging step also resulted in lower ductility at high temperature.
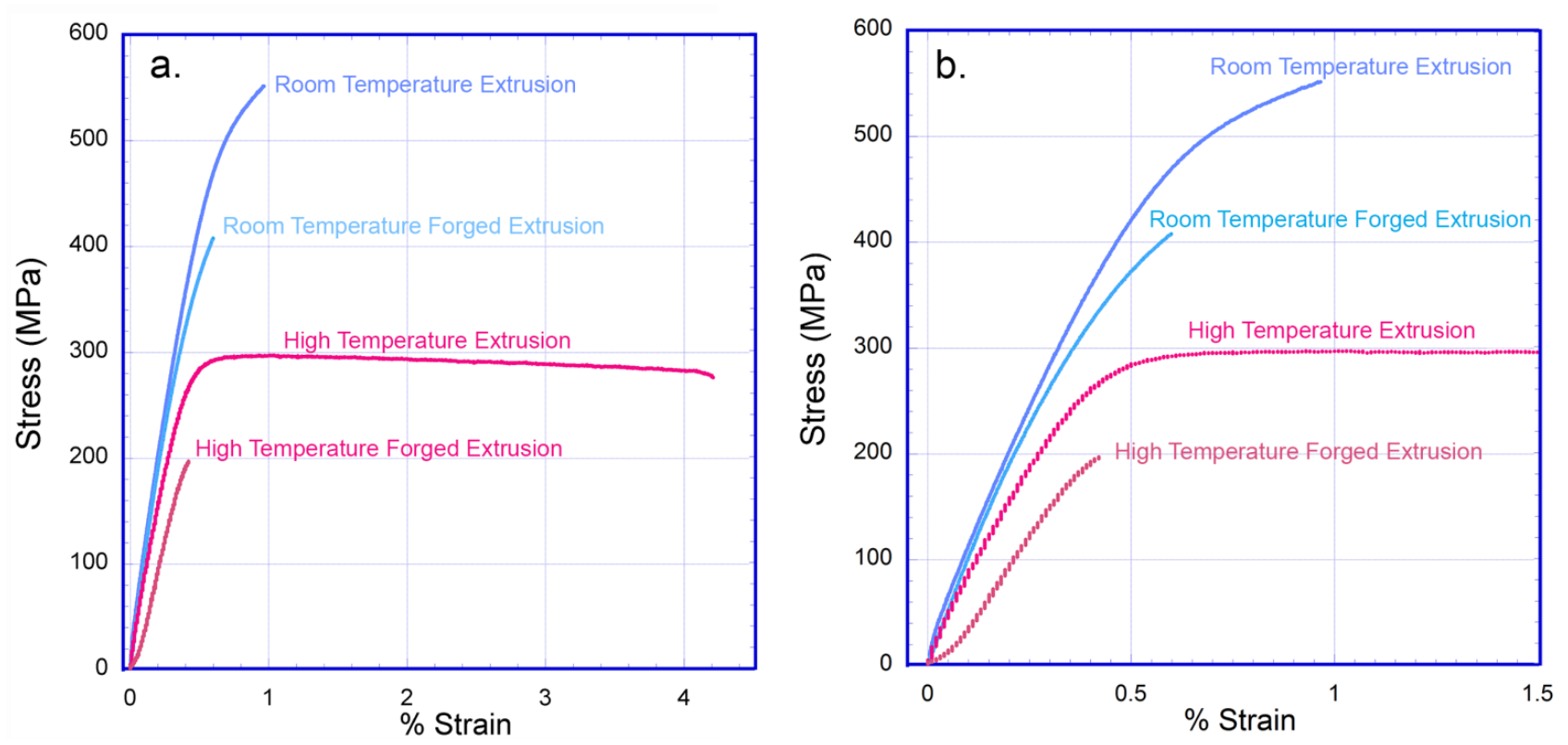

Figure 9. Engineering stress vs. strain plots for the RS aluminum flake material. A (left) shows the full scale test while B (right) has been cropped to better illustrate the linear elastic and yielding behavior.

The plastic region of the stress-strain curve for the high temperature extruded flake shows no strain hardening. Because of the elevated temperature, sufficient internal energy is likely available to initiate dynamic recovery as the material is deformed. The stress required for hot deformation $(\sim 298 \mathrm{MPa})$ represents a dynamic equilibrium between the hardening processes (dislocation generation) and softening processes (dislocation annihilation).[23] As a result, strain hardening is not substantial at high temperatures in the flake material.

Across all samples, it is evident that the $300^{\circ} \mathrm{C}$ test temperature resulted in a reduction in material strength. Strength reduction at elevated temperature is anticipated because dislocation climb and glide become active deformation mechanisms in high temperature regimes. As a result, the generally observed 
trend should be a decrease in strength and an increase in ductility during high temperature testing. In the case of the extruded material, this expected trend is clearly visible. The strain to failure is significantly larger in the HT (high temperature) extrusion compared to the RT (room temperature) extrusion. Deviation from the expected trend (depressed ductility at high temperature) was seen in the forged extrusions. The experimental data shown for the high temperature forged extrusion is typical of all the tests on that material. The ductility did not increase during the high temperature testing in specimens that underwent the added forging step. This lack of increased ductility could be indicative of microstructural differences between the two conditions, and is potentially a result of grain size variation, precipitate formation or phase decomposition. Because of the decrease in high temperature ductility, a microstructural comparison of tensile specimens from the extruded and extruded + forged condition was performed to elucidate any differences the additional high temperature forging step may have caused.

\subsection{Microscopic Evaluation of Flake Material in the Extruded and Extruded + Forged Conditions}

The additional forging step caused the RS flake material to remain at an elevated processing temperature $\left(\sim 480^{\circ} \mathrm{C}\right)$ for a longer amount of time than the extruded material. Because rapidly solidified material contains metastable phases, it becomes important to evaluate and identify potential equilibrium phase formation or microstructural coarsening that could occur during high temperature processing.

Unfortunately, time-temperature-transformation (TTT) curves that would identify temperature regimes leading to phase changes do not exist for this newly developed alloy system. In an effort to understand the tensile strength differences between the extruded flake and the forged extruded flake, scanning electron microscopy was again utilized to evaluate polished cross sections of the failed tensile specimens and results are shown in Figure 10.

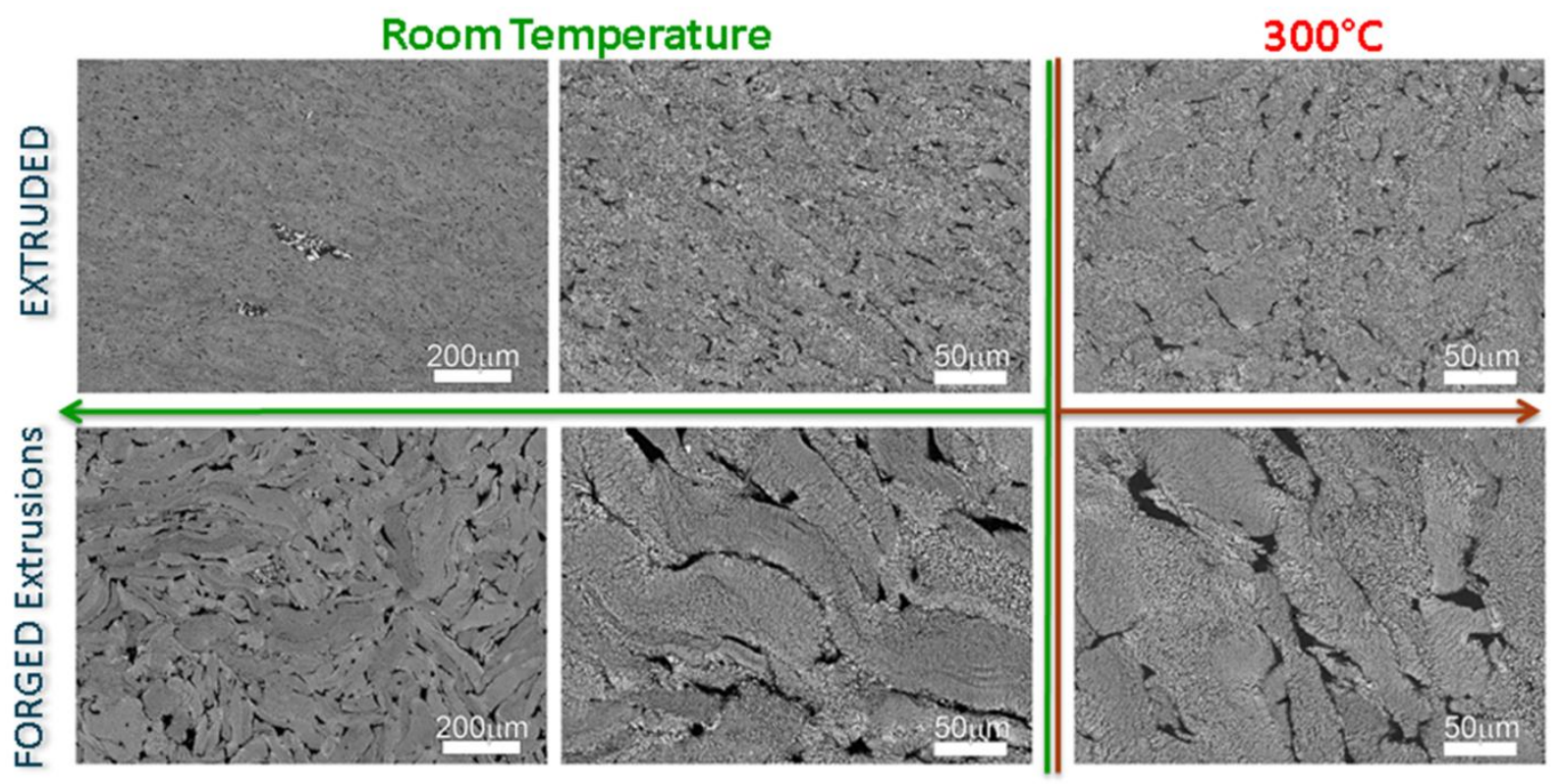

Figure 10. Polished cross sections of the tested tensile specimens are shown for the extruded material (top row) and the forged extrusions (bottom row). The dark contrast in the backscattered electron images shown is $>99 \mathrm{wt} \%$ aluminum and illustrates significant coarsening in the forged extrusion that was not seen in the extruded material. The $300^{\circ} \mathrm{C}$ test temperature when compared to room temperature images appeared to have a negligible effect on the specimen microstructure.

Electron microscopy analysis of the tensile specimens indicated a high degree of microstructural coarsening in the forged extrusions. Backscattered electron contrast and EDS point spectra revealed the presence of aluminum rich veins in the forged extrusions. Results indicate phase segregation in this alloy 
system is likely when extended duration high temperature processing is performed on RS melt spun flake material. Higher material strength would be achieved and maintained by minimizing processing temperatures and duration during consolidation. The $300^{\circ} \mathrm{C}$ test temperature did not indicate addition segregation in either material condition. Results have indicated a need to evaluate phase stability at elevated temperature in this material at temperatures greater than $300^{\circ} \mathrm{C}$.

\subsection{Summary \& Conclusion}

A novel aluminum-based alloy was fabricated via rapid solidification methods and evaluated for high temperature strength and microstructural stability. Two rapid solidification processing methods: rotating cup atomization and melt spinning were utilized to produce shot and flake material, respectively. These raw RS precursors were characterized using electron microscopy. Following microstructural characterization, material from both production methods was consolidated by hot pressing, extruded and tensile tested at room temperature as well as elevated temperature $\left(300^{\circ} \mathrm{C}\right)$. The melt spun flake material, due to its higher cooling rate and more refined microstructure exhibited higher strength than shot material produced by rotating cup processing. Due to its enhanced mechanical response, the flake material was further evaluated following the addition of a tertiary processing step: high temperature forging of the hot pressed and extruded material. The added high temperature forging step resulted in microstructural coarsening in conjunction with decreased strength and ductility.

Observations and analyses of this material indicate melt spinning of this alloy composition followed by hot pressing and extrusion is capable of producing a material with a room temperature yield strength exceeding $500 \mathrm{MPa}$ and a $300^{\circ} \mathrm{C}$ yield strength greater than $275 \mathrm{MPa}$. This work has also demonstrated that significant consideration must be given thermal stability of RS alloys being developed for high temperature applications. Future work will include evaluation of high temperature phase formation and stability in this alloy system.

\subsection{Acknowledgements}

Financial support for this work was awarded by the Department of Energy, Vehicle Technologies Office under Project VTO504000 .The authors would also like to thank CRADA partner Cummins in addition to testing expertise provided by Tyler Kafentzis, Mike Dahl and Karl Mattlin.

\section{References}

1. Krainikov, A.V. and O.D. Neikov, Rapidly solidified high-temperature aluminum alloys. I. Structure. Powder Metallurgy and Metal Ceramics, 2012. 51(7-8): p. 399-411.

2. Cavojsky, M., et al., Microstructure and properties of extruded rapidly solidified AlCr4.7Fe1.1SiO.3 (at.\%) alloys. Materials Science and Engineering: A, 2012. 549(0): p. 233-241.

3. Katgerman, L. and F. Dom, Rapidly solidified aluminium alloys by meltspinning. Materials Science and Engineering: A, 2004. 375-377(0): p. 1212-1216.

4. Michalcová, A., D. Vojtěch, and P. Novák, Selective aluminum dissolution as a means to observe the microstructure of nanocrystalline intermetallic phases from $\mathrm{Al}-\mathrm{Fe}-\mathrm{Cr}-\mathrm{Ti}-\mathrm{Ce}$ rapidly solidified alloy. Micron, 2013. 45(0): p. 55-58.

5. Davis, J.R., J.R.D. Associates, and A.S.M.I.H. Committee, Aluminum and Aluminum Alloys. 1993: ASM International.

6. Uzun, O., et al., Hardness and microstructural characteristics of rapidly solidified Al-8-16 wt.\%Si alloys. Journal of Alloys and Compounds, 2004. 376(1-2): p. 149-157. 
7. Bérubé, G., et al., Phase Stability of Al-5Fe-V-Si Coatings Produced by Cold Gas Dynamic Spray Process Using Rapidly Solidified Feedstock Materials. Journal of Thermal Spray Technology, 2012. 21(2): p. 240-254.

8. Froes, F.H., Y.-W. Kim, and S. Krishnamurthy, Rapid solidification of lightweight metal alloys. Materials Science and Engineering: A, 1989. 117(0): p. 19-32.

9. Barbaux, Y. and G. Pons, New rapidly solidified aluminum alloys for elevated temperature applications on aerospace structures. Journal De Physique IV, 1993. 3: p. 191-196.

10. Dong, X., L. He, and P. Li, Gradient microstructure and multiple mechanical properties of AlSi9Cu alloy ribbon produced by melt spinning. Journal of Alloys and Compounds, 2014. 612(0): p. 2025.

11. Lavernia, E. and T.S. Srivatsan, The rapid solidification processing of materials: science, principles, technology, advances, and applications. Journal of Materials Science, 2010. 45(2): p. 287-325.

12. Zhang, L.Y., et al., Effect of cooling rate on solidified microstructure and mechanical properties of aluminium-A356 alloy. Journal of Materials Processing Technology, 2008. 207(1-3): p. 107-111.

13. Chen, Y.C., M.E. Fine, and J.R. Weertman, Microstructural evolution and mechanical properties of rapidly solidified $A l \square Z r \square V$ alloys at high temperatures. Acta Metallurgica et Materialia, 1990. 38(5): p. 771-780.

14. Rajabi, M., et al., Effect of rapid solidification on the microstructure and mechanical properties of hot-pressed Al-20Si-5Fe alloys. Materials Characterization, 2009. 60(11): p. 1370-1381.

15. Salehi, M., S.G. Shabestari, and S.M.A. Boutorabi, Nanostructure evolution and mechanical properties of rapidly solidified Al3Ni3RE $(Y, \mathrm{Ce})$ alloys. Materials Science and Engineering: A, 2013. 586(0): p. 407-412.

16. Perepezko, J. and R. Hebert, Amorphous aluminum alloys—synthesis and stability. JOM, 2002. 54(3): p. 34-39.

17. Hong, S.J., C. Suryanarayana, and B.S. Chun, Size-dependent structure and properties of rapidly solidified aluminum alloy powders. Scripta Materialia, 2001. 45(12): p. 1341-1347.

18. Otooni, M.A., Elements of Rapid Solidification: Fundamentals and Applications. 2013: Springer Berlin Heidelberg.

19. Anderson, R.E. and e. al, Rapid Solidification Technology: An Engineering Guide. 1993: CRC Press.

20. Dobatkin, V.I., V.I. Elagin, and V.M. Fedorov, Structure of rapidly solidified aluminum alloys. Advanced Performance Materials, 1995. 2(1): p. 89-98.

21. Kaufman, J.G., Properties of Aluminum Alloys: Tensile, Creep, and Fatigue Data at High and Low Temperatures. 1999: ASM International.

22. Belov, N.A., Aksenov, A.A., and Eskin, D.G., Iron in Aluminum Alloys. Advances in Metallic Alloys, ed. Fridlyander; J.N. and E. D.G. 2002: Taylor and Francis. 341.

23. Beddoes, J. and M.J. Bibby, 3 - Stress and strain during deformation, in Principles of Metal Manufacturing Processes, J. Beddoes and M.J. Bibby, Editors. 1999, Butterworth-Heinemann: Oxford. p. 76-98. 